\title{
Megabecquerel per Microliter
}

National Cancer Institute

\section{Source}

National Cancer Institute. Megabecquerel per Microliter. NCI Thesaurus. Code C71169.

A metric unit of volumetric radioactivity concentration defined as a concentration of a radionuclide with an activity equal to one million becquerels per unit volume equal to one millionth of a liter. 